\title{
Nursing Knowledge for the 21st Century: Opportunities and Challenges
}

\author{
Ada Sue $H$ inshaw
}

\begin{abstract}
Journal of Nursing Saholarship, 2000; 32:2, 117-123. @2000 Sigma Theta Tau Intranational.
\end{abstract}
[Key words: research priorities, international]

$\mathrm{n}$ the final two decades of the 20th century, an unprecedented explosion of nursing knowledge guided practice and advanced the health and well-being of individual clients, families, and communities. The rapidly increasing resources available for nursing research haveopened numerous opportunities for studying important questions and issues in promoting health, ameliorating the sideeffects of illness and the consequences of treatments, whileoptimizing the health outcomes of people and their families.

Concurrently, major shifts haveoccurred in providing health care, including: emphasis on community-based care; focus on health promotion and risk reduction; increased severity of illness in inpatient facilities coupled with major cost reductions and restructuring; increased incidence of chronic illnesses especially in the growing number of elderly; growth of integrated health care systems using managed care approaches across multiple types of health care settings; and increased need for a diverse complement of health care providers to assure access to care and high-quality outcomes.

Thesehealth caretrends in many countries provideadditional opportunities for nurses and nurse practitioners to contribute in new roles and settings. $M$ any of these trends highlight historical strengths of thenursing profession, such as providing care in the community, promoting health and reducing the risks of certain disease conditions, managing chronic illnesses with individuals and their families, and organizing and managing the care of clients among multiple settings. H ow ever, these same opportunities challenge nurses to provide the research base necessary to make wise decisions with relatively predictable outcomes under these new and different health care trends. The evolving knowledge base of thelast 20-someyears indicates nurses' commitment to the clinical issues that patients, families, and communities confront, as well as the changing patterns and needs of the health care systems.

Theopportunities resulting from thesechanges present several additional challenges, particularly the needs for a global perspective in the evolving knowledge base, explicit strategies to improve nursing practice, and influence on health policy. Knowledge for nursing must be built on a broader platform than any one country's health care trends and the assessment of clinical questions and issues. Sigma Theta Tau International's Strategic Plan for 2005 articulates that vision: "To create a global community of nurses who lead in using scholarship, knowledge, and technology to improvethehealth of theworld's people."

A nalysis of priorities in different parts of the world, follow ed by comparisons across countries, provides a foundation for efforts to meet that goal. Because of my experiencein theUnited States (US) and the volume of literature about A merican nursing priorities, I will first review the situation in the US at the turn of the century.

The generation of nursing knowledge for the 21st century will be considered from three perspectives: (a) an analysis of the top five nursing research priorities evident in the American nursing literature of the past 5 years, (b) future directions for nursing research outlined by 60 American investigators in a 1999 publication on clinical nursing research ( $\mathrm{H}$ inshaw, Feetham, \& Shaver, 1999), and (c) international nursing research priorities from a number of countries. The analysis indicates similarities and differences to provide a global perspective and to identify opportunities for international studies.

\section{Nursing Research Priorities in the United States}

Five major nursing research priorities were categorized from nine articles published 1994 to 1999. These publications were produced by A merican professional organizations or by leading researchers in a clinical field. All of the priorities wereidentified from systematically conducted, funded research studies of which six used the Delphi technique. Thus, the priorities reflect the judgments of hundreds to thousands of clinical experts and nurse researchers in each field.

The five A merican nursing research priorities generated from nine sources are show in Table 1 . The priority category was listed if three or more of the sources cited the area. The

Ada Sue Hinshaw, RN, PhD, FAAN, Rho \& Beta Mu, Dean and Professor, University of Michigan, School of Nursing, Ann Arbor. This article is based on a paper presented at Sigma Theta Tau International's Biennial Convention, San Diego, CA, November 6-9, 1999. Correspondence to Dr. Hinshaw, University of Michigan School of Nursing, 400 N. Ingalls, Ann Arbor, Ml 48109-0482. E-mail: ahinshaw@umich.edu

Accepted for publication November 9, 1999. 


\section{Table 1. Top Five American Nursing Research Priorities}

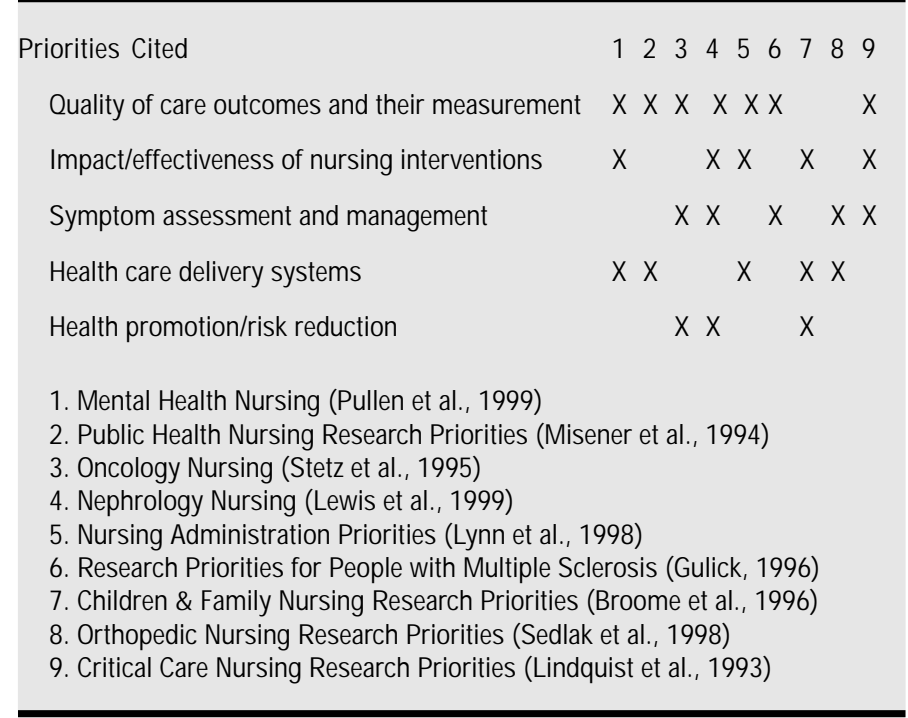

priority areas identified for A merican nursing research at the turn of the century were: quality of care outcomes and their measurement, impact or effectiveness of nursing interventions, symptom assessment and management, health care delivery systems, and health promotion/risk reduction. These priorities were evident in the literature for many clinical nursing research fields. The emphasis on quality of care outcomes indicates the profession's commitment to identify and measure nursing sensitive outcomes as both clinical measures and research tools. The priorities of (a) effectiveness of nursing interventions, (b) symptom assessment and management, and (c) health care delivery systems were comparable. The only surprise was that the health promotion/ risk reduction category was cited in only three of the nine sources. As community care through primary care centers becomes more prevalent, as predicted in the PEW Report (1995), health promotion/risk reduction research will increase in importance.

The second approach to examining future directions for nursing research is through the words of 60 major nurse researchers in the text, $\mathrm{H}$ andbook for Clinical $\mathrm{N}$ ursing Research (H inshaw et al., 1999). For the major areas of evolving nursing science, the authors analyzed the state of the science and projected these directions for nursing research into the 21st century: (a) critical health needs of communities and vulnerable populations, (b) practice strategies and outcomes, (c) family health and transitions, (d) health promotion/risk reduction, (e) biobehavioral manifestations of health and illness, (f) women's health, (g) health and illness of older adults, (h) environments for optimizing client outcomes, (i) genetics research, and (j) end-of-life research.

Oritical Health Needs of Communities and Vulnerable Populations

In examining the clinical nursing research focused on vulnerable populations, the authors critically review ed several major populations: individuals, families, and communities in rural areas (Weinert \& Burman, 1999), research with immigrants and refugees (Lipson \& M eleis, 1999), cultural interventions for ethnic groups of color (Tripp-R eimer, 1999), and community-focused interventions and outcome strategies (M agilvy, Brown, \& M oritz, 1999). Two major future directions were evident from the studies in this area. First, clinical nursing research should be systematic and attuned to cultural sensitivity and competence, whether the studies are focused on individuals, families, and communities from rural backgrounds or people of color or immigrants or refugees. Second, most of clinical nursing research is focused on the individual or the family, as in caregiver studies. This perspective should be broadened to include population-based and community-focused research, such as interventions and outcomes in smoking cessation programs. Such research targets total communities with educational interventions and the outcomes are measured by community changes such as no-smoking policies in restaurants or public settings.

\section{Cinical Nursing Practice Strategies and Nursing Sensitive Outcomes}

This area of clinical research includes therapeutic actions and outcomes to promote physiological stability. Two areas are of particular concern in the knowledge base: therapeutic actions and outcomes for preterm infants, and the development of outcomes that are sensitive to nursing interventions. Future directions should focus on several major areas. Therapeutic nursing actions and outcomes that measure their effects require study across the live span. The developmental stage with less information or research is the middle-aged adult. M ore studies exist concerning actions needed for prenatal care, care of preterm infants, and care of the elderly, compared to studies focused on therapeutic actions and outcomes best suited for middle-aged adults. A nother needed direction is continuation of the focus on identifying and developing measurement instruments for therapeutic outcomes sensitive to nursing interventions (Holzemer \& Henry, 1999). A task force of the A merican A cademy of $\mathrm{N}$ ursing identified five nursing sensitive outcomes for study: achievement of appropriate self-care, demonstration of health-promoting behaviors, health-related quality of life, patient perception of being well cared for, and symptom management ( $M$ itchell, $\mathrm{H}$ einrich, $\mathrm{M}$ oritz, \& H inshaw, 1997).

\section{Families in Health, IIIness, and Life Transitions}

In the area of family health, nurse researchers have focused on normative family transitions and health outcomes, using a strong developmental as well as functional or dysfunctional perspective (M cCubbin, 1999; Gilliss \& Knafl, 1999). N urse scientists in this area assert that this field of study is strongly interdisciplinary, and "no one discipline owns the family" (Gilliss \& Knafl, 1999, p. 245). H owever, their conclusion is that " $N$ ursing literature does not provide significant empirical evidence for the effect of nursing interventions with families" (Gilliss \& Knafl, 1999, p. 245). This criticism indicates the research that is needed in this area and challenges nurse 
investigators to broaden their studies to include families as well as individuals. A particularly important area for study is the effect of the family on the illness experience of patients and how and when nurses should intervene.

\section{Health Promotion/Risk Reduction}

N urses' time honored and acknowledged focus on health promotion is well understood among the disciplines. N urses focus more on promoting health and preventing illness than on curing disease. During the early years of the $\mathrm{N}$ ational Institute of N ursing Research (N IN R ), a major investment was made in health promotion research, especially health promotion with adolescents. However, health promotion studies encompass all developmental stages, such as prevention of premature infancy, low ering cardiovascular disease in children and adolescents, health promotion in theworkplace, and health promotion for women and for the elderly (Pender, 1999).

$\mathrm{H}$ ealth promotion is an area of strength for the knowledge base for nursing practice, but added directions are needed. M ost of the research in health promotion has focused on behavioral strategies to facilitateindividuals' adopting healthy behaviors, for example, using exercise programs with adolescents to draw them into fun, healthy behaviors instead of risky behaviors such as drinking and using drugs. Studies in the future must also focus on long-term maintenance strategies for adhering to healthy behaviors over a lifetime. In addition, the costs of the strategies for maintaining healthy lifestyles are not well understood.

\section{Biobehavioral Manifestations of Health and IIIness}

This area of research reflects the major problems in clinical nursing research related to symptom assessment and management, especially biologically based and physically experienced symptoms which have strong perceptual and behavioral components (Lindsey \& Shaver, 1999). The major symptoms that have been examined include mobility and altered physical activity (Smith \& M acVicar, 1999), dyspnea (Carrieri-Kohlman \& Janson, 1999), pain (Ferrell, 1999), urinary and fecal incontinence (D ougherty \& Jensen, 1999), nausea and vomiting (H eitkemper, 1999), and sleep and fatigue (Shaver, 1999). Although a relatively strong body of research is devel oping in each of these areas, much additional work is needed. M ultiple new creative interventions for managing these symptoms and others should be developed and tested, especially interventions clearly dictated by the biological and behavioral mechanisms underlying them. Practitioners and researchers need a better understanding of the behavioral and perceptual components of these symptoms. To what extent is the biological symptom influenced by perceptual factors? W hat factors are most active under what clinical conditions? What interventions most effectively influence the biologically based symptom and its perceptual and behavioral components?

\section{Women's Health}

$\mathrm{N}$ urse researchers have contributed strongly to the field of women's health. Significant contributions have been made especially to understanding menarche, menstruation and menstrual symptoms, and menopause, as well as women's sexuality across the lifespan. According to Woods (1999), nursing research has led other disciplines in relation to the assessment, management, and measurement of symptoms related to these areas. Violence against women, particularly male battery of women, has been a focal point for nursing research. This body of research has "informed practice about risk situations for women and promotes screening for violence and identification of women who have been battered" (Woods, 1999, p. 458). The primary contribution of nursing research to women's health is the philosophical "whole person" approach including "body-mind-emotions-social" relationships (Woods, M itchell, \& Taylor, 1999, p. 502) to replace the previous focus on disease and illness.

Future directions for nursing research are numerous: the relationship of women's work to women's health, not only worksite risks to reproductive processes but also the stress implications of performing multiple roles; greater understanding of the numerous symptoms of menstruation from the biobehavioral perspective, for instance swelling and cramps; and in the field of infertility, questions about psychological consequences to infertility treatment, effect on the family, and whether women who became pregnant following extensive infertility treatments respond to or experience pregnancy, labor, and delivery differently from others. Women's sexuality should be studied from the "normal" perspective because most of this research has been focused on disease. In the field of violence against women, nurse researchers have made major contributions to understanding abuse during pregnancy (Campbell \& Parker, 1999), and have provided clinical mechanisms to screen for battering. Future directions in this area of research include broadening the screening and diagnosis of "battering" in all clinical settings, studying the effects of violence against women on their children, and understanding "battering" as a cultural phenomenon.

\section{Health and IIIness of Oder Adults}

$\mathrm{N}$ ursing research has been focused heavily in three areas in studying the health and illness of older adults: (a) activities of daily living and maintaining the independence of elders (Roberts, 1999), (b) managing cognitive impairment and depression in the elderly (Beck, Cronin-Stubbs, Buckwalter, \& Rapp, 1999), and (c) providing supportive care environments for the elderly (Phillips \& Ayres, 1999). M ost gerontological nursing interventions " are designed to reduce the demands (stress) of the environment and to enhance elders' physical, cognitive, or emotional capacities in some way" (Archbold, 1999, p. 561). Research is needed to identify older adults who are at high risk for loss of independence in daily activities or who are approaching increased dependence. In addition, for individuals with dementia, several research opportunities are evident: outcome measures that detect changes in well-being and affect interventions for enhancing and maintaining memory, and interventions to enhance optimism and self-esteem. The environmental context of older 
adults is known to be extremely important to retaining control, autonomy, and memory. Researchersfor the futurealso should focus on creating environments in multiple settings to support older adults. What environmental interventions are most effective and what outcomes are desired?

\section{Environments for Optimizing Cient Oitcomes}

$\mathrm{N}$ urse investigators have studied health care environments and their influence on client outcomes, particularly in relation to restructuring or redesigning acute care hospitals and transitional environments. A series of investigations has been conducted to study the influence of restructuring factors on patients' outcomes. Structuring for more professional environments, in which nurses have more control over the environment, has enhanced satisfaction for staff and patients. Redesign, which has reduced numbers of employed professional nurses, has been shown to be related to increased morbidity and mortality of patients (Aiken, Smith, \& Lake, 1994). With the rapidly changing environments and nursing care patterns in acute care facilities, research for the future is critical for predicting the influence of these changes on patient and family outcomes and to intervene in destructive environments.

Thetransitional environment research of two colleagues and their teams-Brooten \& N aylor (1995); N aylor, Brooten, Campbell, Jacobsen, M ezey, Pauly, and Schwartz (1999)-have made major contributions concerning handling the early discharge of patients from acutecarehospitals. The successfully tested intervention, in a series of experimental and control group trials, included systematic discharge planning and follow-up in the community by advanced practice nurses. Consistently the outcomes, whether for premature infants or hospitalized older adults, have been higher quality outcomes, such as fewer rehospitalizations, greater satisfaction with the experience, and lower costs. Future research is needed to identify those individuals who areat high risk during transitions in the health care systems and would particularly benefit from this type of intervention program. What sociodemographic, clinical, and health care system factors make patients and families more at risk for poor outcomes during transition?

\section{Genetics Research}

The area of genetics and defining the human genome offers many opportunities for future research by nurses, ranging from basic biological studies to clinical decision making and behavioral interventions. According to Sigmon and her colleagues at NINR (1997), nurse researchers can make significant contributions to understanding the geneenvironment-behavioral interface, the development and use of biological, psychosocial, and neuroimmunologic markers, basic research, biologic psychosocial intervention and counseling related to genetic health, developing and testing cognitive models for decision making regarding genetic factors and genetic therapies, and investigating new delivery models for health care given the evolving genetic knowledge base. This new and exciting field of study is one in which nurse researchers will need to play a major role so that the evolving knowledge base is structured within a "holistic" understanding of the person.

\section{End-of-Life Research}

Another major field of clinical study in which nurses as clinicians and investigators should be major contributors is end-of-life research. To date, nurses have contributed palliative care perspectives but the focus of nursing research should be broadened to encompass major decision making processes that occur for patients and their families, clinically identifying the end-of-life transition stage, what is important to patients and their families, and how they want to experience the end of life. Tilden (1999) observed that a "wave of national initiatives" is being undertaken to improve end-of-life care. What nursing interventions flow from the guiding ethical principles of autonomy, beneficence, and justice for this period of health care? H ow do nurses identify the time in a critical care unit when the goal is no longer to save life at all cost but to facilitate a dignified death?

This review of major clinical nursing research fields of study indicates that many opportunities for important research programs are open to the discipline. Although the foundation for a know led ge base for nursing practice is well established, many more opportunities lie ahead. Three recurring themes are evident in the nursing research literature. 0 ne, a strong emphasis on intervention research is needed to provide a stronger, more predictable base for nursing practice. Two, to ensure the relevance of nursing research to practice, intradisciplinary collaboration among expert clinicians and investigators is critical. Three, clinical problems are highly complex and require multiple perspectives, calling for multidisciplinary research partners.

\section{International Nursing Research Priorities}

Recall that the overall vision is to create a "global community of nurses generating and using scholarship and knowledge to optimize nursing practice for individuals, families, and communities." N urses in numerous countries are generating and conducting research, thus providing opportunities for cross-cultural and cross-national studies of clinical and health care system problems of common interest. The challenges are many; for example, establishing international networks, understanding different cultural perspectives and adapting the research accordingly, and obtaining funding for international projects. The nursing research priorities for many countries show many similar interests and opportunities for collaboration.

To consider areas in which international research collaboration could occur, a series of nursing research priorities from several countries and regions of the world are outlinedGreat Britain, Africa, Thailand, and the N ordic countries of Sweden, N orway, Finland, Denmark, and Iceland. The European Work Group of N urse Researchers has also identified nursing research priorities, representing the consensus of the European Union Countries. A comparison of these sets of priorities, including those from the United States, will provide important information about similarities and differences as well as opportunities for international collaboration. 
$N$ urses in Great Britain have defined six nursing research priorities (Kitson, M cM ahon, Rafferty, \& Scott, 1997):

- Research into patients' perspectives of care and how they are assessed;

- The role of informal care-givers and how health and social care are or will be integrated;

- $\mathrm{N}$ ursing interventions (including preventive care, treatment and support) and nurse-led services;

- Access to and exit from health services, and nurses' roles in this process;

- Chronicity and how to facilitate coping with chronic illness;

- Evaluating the effect of new technologies on nursing practice.

These priorities can be compared to those in the $\mathrm{N}$ ordic countries (Hinshaw, 1997):

- Promoting health and well-being across the life span;

- Symptom management in chronic illness and in general common symptoms;

- Care of the elderly;

- Q uality of care balanced with cost outcomes;

- Restructuring health care systems;

- Self-management of health and illness;

- Theoretical and philosophical perspectives of developing knowledge in nursing practice.

Priorities in Thailand were formulated somew hat differently (M ahidol University Faculty of N ursing, 1996). Nurse researchers and clinical experts first defined four major nursing concerns and then outlined four major health problems. The concerns about health promotion and prevention of infectious diseases are very evident.

N ursing concerns:

- Prevention of major health problems;

- H ealth promotion;

- Improvement of nursing intervention;

- Development of nursing science;

M ajor health problems:

- AIDS;

- Infectious diseases;

- N oncommunicable diseases;

- M other and child care.

In Africa, the nursing research priorities indicate a different set of social, cultural, and economic conditions (Henry \& Chang, 1998). The high prevalence of HIV/AIDS is a major issue. In addition, the periodic outbreak of war-like conditions dictates certain research concerns. The African priorities include:

- Prevention of and care of individuals with HIV/AIDS;

- H ome care of individuals with AIDS;

- Social, cultural, economic, and political activities that affect the elderly;

- Epidemiological studies of HIV/AIDS;

- Epidemiological studies of risk factors in work environment;

- Effects of war and armed conflicts on health and general well-being, especially women and children;

- Studies of mental and social health of women.
In 1999, the European Work G roup priorities were identified by nurse researchers, educators, and clinical experts from 19 European countries (Building a European N ursing R esearch Strategy, 1999). These countries are at very different points in their development of nursing research and in their access to resources for funding nursing research. From this diversegroup five nursing research priorities were identified:

- Effective care and continuity among different settings (hospital and community) for elderly people with health problems;

- Effectivestrategies to promotehealth lifestyles in childhood and adolescence;

- Effect of variations in nursing skill-mix on quality and costs of care and patient outcomes;

- Effectiveness of nursing interventions for symptom management (e.g. pain, dyspnea, fatigue, anxiety and stress);

- Evaluation of innovative, community-based partnership models for nursing and health care of vulnerable populations (women, immigrants, people without homes, and so on).

Table 2 shows that four of the priorities are shared by three or more countries and regions: promoting health, caring for the elderly, studying health care systems, and managing symptoms. The emphasis on health promotion is strong, particularly in relation to its lower priority in U.S. reports. A t least two of the areas also shared a concern for care issues with chronic illnesses, the patient's perspective and selfmanagement of health and illness, balancing quality of care outcomes with the cost of care, improving nursing interventions, and developing nursing science. The U.S. priorities are similar, that is, care issues with chronic illnesses, care of the elderly, quality of care outcomes balanced with costs, improvement and study of nursing interventions, and the assessment and management of symptoms.

\section{Nursing Knowledge for Practice}

The dramatic number of opportunities and challenges for generating knowledge for the nursing discipline and professional practice are both exciting and awe-inspiring in the review of national and international nursing research priorities and future directions for nursing research. But no challenge is greater than translating nursing knowledge into nursing practice and using knowledge to shape health policy. A majority of the authors addressing future directions for nursing research ended their comments by discussing the need for and challenge of disseminating, utilizing, or translating the findings of research into practice.

Although the need to translate nursing knowledge into practice is readily acknowledged, models and strategies for accomplishing this challenge are not so evident. In the early phase of increased resources for nursing research at the $\mathrm{N}$ ational Center for N ursing Research (NCNR) in 1987, the decision was made to invest funds in generating the knowledge base through research and to facilitate the development of major research programs for the discipline. This strategy was 
Table 2. International Nursing Research Priorities

\begin{tabular}{|c|c|c|c|c|c|c|}
\hline & $\begin{array}{l}\text { Nordic } \\
\text { Countries }\end{array}$ & Thailand & Great Britain & Africa & European Work Group & United States \\
\hline Health promotion & $\mathrm{x}$ & $\mathrm{X}$ & $\mathrm{X}$ & $\mathrm{X}$ & $\mathrm{X}$ & $\mathrm{X}$ \\
\hline Care of the elderly & $\mathrm{x}$ & & & $\mathrm{x}$ & $\mathrm{x}$ & $\mathrm{x}$ \\
\hline Chronic illness/care issues & $x$ & & $\mathrm{X}$ & & & \\
\hline Patient perspective/self-management of health and illness & $\mathrm{x}$ & & $\mathrm{x}$ & & & \\
\hline Health care systems & $\mathrm{x}$ & & $\mathrm{x}$ & $\mathrm{x}$ & & $\mathrm{x}$ \\
\hline Quality of care outcomes_-balanced with cost & $\mathrm{x}$ & & & & $\mathrm{X}$ & $\mathrm{x}$ \\
\hline Improvement of nursing interventions & & $x$ & $x$ & & & $\mathrm{X}$ \\
\hline Symptom management & & & $\mathrm{X}$ & $\mathrm{x}$ & $x$ & $x$ \\
\hline Development of nursing science & $x$ & $x$ & & & & \\
\hline
\end{tabular}

successful; a strong beginning foundation of research to guide nursing practice exists. $\mathrm{N}$ ow, attention is needed to also address the development and evaluation of models for dissemination, utilization, and translation of that knowledge into practice. The study, "Conduct and Utilization of N ursing R esearch" by Horsley, Crane, Reynolds, and Haller (1981), based on the model of diffusion processes, provided one model for beginning consideration for translating knowledge into practice. Stetler and DiM aggio (1991) and other colleagues have written extensively on models and factors in research utilization.

A nother important strategy, which should be developed and evaluated for its effectiveness in translating knowledge into nursing practice, is evidence-based practice. This concept is under extensive discussion in most health care settings and is being integrated into many undergraduate programs in nursing. By definition, evidence-based practice requires the synthesis of knowledge from research, retrospective or concurrent review of records, quality improvement and risk data, standards of care, infection control data, pathophysiological knowledge, cost-effectiveness analysis, benchmarking data, patient preferences, and clinical expertise (Goode \& Piedalue, 1999). How to haveall this information at the fingertips of professional nurses for critical analysis and decision making requires improved strategies. O nly then can nurses integrate information from which intervention decisions can be tailored to clients. Thus, one of the future directions for research is to identify the factors in the environment, including sophisticated information systems, that will facilitate evidence-based practice in health care organizations of all types. M ore broadly, whether the strategy is evidence-based practice or something else, the factors to facilitate the translation of knowledge into nursing practice should be identified and tested in different approaches to utilization or application.

Building the relationship between nursing research and health policy is an important challenge for the nurses. The linking of health policy and nursing research is logical given nurses' commitment to the generation of knowledge for a purpose: improving the health for individuals, families and communities, ameliorating the effects of disease, and structuring health care environments to optimize client and cost outcomes. The research programs of the discipline are expected not only to lead to changes in nursing practice but also to provide perspective and information for influencing and shaping health policy (Feetham \& M eister, 1999). Policy formation occurs within health care organizations as well as in state and national health programs ( $\mathrm{H}$ inshaw, 1988). The challenge is to frame nursing research and use substantiated findings to shapehealth policy at all levels to maximizethehealth of individuals, families, and communities.

\section{Conclusions}

$M$ any avenues for generating nursing knowledge provide multiple opportunities for the future. A strong beginning foundation has been built, and the areas of further study are exciting and far reaching toward enhancing the profession's ability to affect the experience of health and illness of individuals, families, and communities. Challenges exist around the world to advance the depth of the knowledge base for nursing while expanding the areas of study and developing global perspectives for nursing research through international collaboration. The greatest challenge is to develop the models and strategies for translating the evolving knowledge base into nursing practice and to use it to shape health policy.

As nursing moves into the 21st Century, the explosion of knowledge to guide nursing practice should and will be celebrated. Concurrently, theenergy from that celebration must be focused on pursing multiple research opportunities and meeting the exciting challenges ahead. JNS

\section{References}

Aiken, L.H., Smith, H.L., \& Lake, E.T. (1994). Lower M edicare mortality among a set of hospitals known for good nursing care. M edical C are, 32, 771-787.

Archbold, P.G. (1999). Older adults: Health and illness issues. In A.S. $\mathrm{H}$ inshaw, S.L. Feetham, \& J.L.F. Shaver (Eds.), H andbook of clinical nursing research (561-562). Thousand $O$ aks, CA: Sage.

Beck, C.K., Cronin-Stubbs, D., Buckwalter, K.C., \& Rapp, C.G. (1999). $M$ anaging cognitive impairment and depression in the elderly. In A.S. $\mathrm{H}$ inshaw, S.L. Feetham, \& J.L.F. Shaver (Eds.), $\mathbf{H}$ andbook of clinical nursing research (579-593). Thousand $O$ aks, CA: Sage. 
Brooten, D., \& N aylor, M.D. (1995). N urses' effect on changing patient outcomes. Image: Journal of N ursing Scholarship, 27, 95-99.

Building a European N ursing Research Strategy. (1999, M arch). Euroconference, Salamanca, Spain: Instituto de Salud Carlos III.

Campbell, J., \& Parker, B. (1999). Clinical nursing research on battered women and their children: A review. In A.S. H inshaw, S.L. Feetham, \& J.L.F. Shaver (Eds.), H andbook of clinical nursing research (535-546). Thousand O aks, CA: Sage.

Carrieri-Kohlman, V., \& Janson, S. (1999). M anaging dyspnea. In A.S. $H$ inshaw, S.L. Feetham, \& J.L.F. Shaver (Eds.), Handbook of Clinical N ursing R esearch (379-390). Thousand O aks, CA: Sage.

Dougherty, M .C., \& Jensen, L.L. (1999). M anaging urinary and fecal incontinence. In A.S. H inshaw, S.L. Feetham, \& J.L.F. Shaver (Eds.), H andbook of Clinical N ursing Research (407-421). Thousand O aks, CA: Sage.

Feetham, S.L., \& M eister, S.B. (1999). N ursing research of families: State of the science and correspondence with policy. In A.S. H inshaw, S.L. Feetham, \& J.L.F. Shaver (Eds.), $\mathbf{H}$ andbook of clinical nursing research (251-271). Thousand O aks, CA: Sage.

Ferrell, B.R. (1999). M anaging pain. In A.S. H inshaw, S.L. Feetham, \& J.L.F. Shaver (Eds.), $\mathbf{H}$ andbook of clinical nursing research (395-403). Thousand O aks, CA: Sage.

Gilliss, C.L., \& Knafl, K.A. (1999). N ursing care of families in non-normative transitions: The state of science and practice. In A.S. H inshaw, S.L. Feetham, \& J.L.F. Shaver (Eds.), $\mathbf{H}$ andbook of clinical nursing research (231-245). Thousand O aks, CA: Sage.

Goode, C.J., \& Piedalue, F. (1999). Evidence-based clinical practice. Journal of N ursing Administration, 29(6), 15-21.

H eitkemper, M . (1999). M anaging nausea and vomiting. In A.S. H inshaw, S.L. Feetham, \& J.L.F. Shaver (Eds.), $\mathbf{H}$ andbook of clinical nursing research (425-431). Thousand O aks, CA: Sage.

Henry, B.M ., \& Chang, W.Y. (1998). N ursing research and priorities in Africa, Asia, and Europe. Image: Journal of $\mathbf{N}$ ursing Scholarship, 30, $115-116$

H inshaw, A.S. (1988). Using research to shape health policy. $\mathbf{N}$ ursing O utlook, 36(1), 21-4.

H inshaw, A.S. (1997). Building excellence in science: Setting priorities for knowledge development. In E. H amrin \& M . Lorensen (Eds.), N ordic symposium, perspectives on priorities in nursing science ( $\mathrm{N} 0.1,15-28$ ). Stockholm, Sweden: Vardalstiflelsen.

H inshaw, A.S. (1999). Evolving nursing research traditions: influencing factors. In A.S. H inshaw, S.L. Feetham, \& J.L.F. Shaver (Eds.), H andbook of clinical nursing research (19-28). Thousand O aks, CA: Sage.

H inshaw, A.S., Feetham, S.L., \& Shaver, J.L.F. (Eds.). (1999). H andbook of clinical nursing research. Thousand $O$ aks, CA: Sage.

H olzemer, W.L., \& H enry, S.B. (1999). Therapeutic outcomes sensitive to nursing. In A.S. H inshaw, S.L. Feetham, \& J.L.F. Shaver (Eds.), H andbook of clinical nursing research (185-195). Thousand O aks, CA: Sage.

H orsley, J.A., Crane, J., Reynolds, M .A., \& H aller, K.B. (1981). Using research to improve nursing practice: $A$ guide. In, Conduct and utilization of research in nursing project. $N$ ew York: Grune \& Stratton.

Kitson, A., M cM ahon, A., R afferty, A.M ., \& Scott, E. (1997). H igh priority. N ursing Times, 93(42), 15-21.

Lewis, S.L., Cooper, C.L., C ooper, K.G., \& Bonner, P.N . (1999). Research priorities for nephrology nursing: American Nephrology $\mathrm{N}$ urses' Association's Delphi Study. AN N A Journal, 26(2), 215-25.

Lindsey, A.M ., \& Shaver, J.L.F. (1999). Biobehavioral manifestations of health and illness. In A.S. Hinshaw, S.L. Feetham, \& J.L.F. Shaver (Eds.), $\mathbf{H}$ andbook of clinical nursing research (361-362). Thousand $O$ aks, CA: Sage.

Lindquist, R ., Banasik, J., Barnsteiner, J., B eecroft, P.C., Prevost, S., R iegel, B., Sechrist, K., Strzelecki, C., \& T itler, M . (1993). Determining AACN 's research priorities for the $90 \mathrm{~s}$. American Journal of Critical Care, 2(2), 110-117.

Lipson, J.G., \& M eleis, A.I. (1999). R esearch with immigrants and refugees. In A.S. H inshaw, S.L. Feetham, \& J.L.F. Shaver (Eds.), H andbook of clinical nursing research (87-101). Thousand Oaks, CA: Sage.

Lynn, M .R ., Layman, E.L., \& Englebardt, S.P. (1998). N ursing administration research priorities - a national Delphi study. Journal of $\mathbf{N}$ ursing Administration, 28(5), 7-11.

M agilvy, J.K., Brown, N.J., \& M oritz, P. (1999). Community-focused interventions and outcomes strategies. In A.S. H inshaw, S.L. Feetham, \&
J.L.F. Shaver (Eds.), H andbook of clinical nursing research (125-141). Thousand O aks, CA: Sage.

M ahidol University Faculty of N ursing. (1996, M arch 4-8). Thailand nursing research priorities, nursing research. TheK ey to $\mathrm{N}$ ursing Science R esearch Conference, $M$ ahidol University, Bangkok, Thailand.

M cC ubbin, M . (1999). N ormative family transitions and health outcomes. In A.S. H inshaw, S.L. Feetham, \& J.L.F. Shaver (Eds.), H andbook of clinical nursing research (201-220). Thousand O aks, CA: Sage.

M isener, T.R., Watkins, J.G., \& O ssege, J. (1994). Public health nursing research priorities: A collaborative D el phi study. Public $\mathbf{H}$ ealth $\mathbf{N}$ ursing, 11(2), 66-74.

M itchell, P.H ., H einrich, J., M oritz, P., \& H inshaw, A.S. (1997). O utcome measures and care delivery systems: Introduction and purposes of conference. M edical C are, 35(11), N S1-N S5.

N aylor, M .D., B rooten, D., C ampbell, R . Jacobsen, B.S., M ezey, M . D., Pauly, M.V., \& Schwartz, J.S. (1999). Comprehensive discharge planning and home follow-up of hospitalized elders: A randomized clinical trial. Journal of the American M edical A ssociation (JAM A), 281(7), 613-620.

Pender, N. (1999). H ealth promotion and risk reduction. In A.S. H inshaw, S.L. Feetham, \& J.L.F. Shaver (Eds.), $\mathbf{H}$ andbook of clinical nursing research (273-274). Thousand O aks, CA: Sage.

PEW H ealth Commission Report. (1995). C ritical challenges: R evitalizing the health professions for the twenty-first century. San Francisco, CA: UCSF Center for the $\mathrm{H}$ ealth Professions.

Phillips, L.R., \& Ayres, M. (1999). Supportive and nonsupportive care environments for the elderly. In A.S. H inshaw, S.L. Feetham, \& J.L.F. Shaver (Eds.), $\mathbf{H}$ andbook of clinical nursing research (599-622). Thousand O aks, CA: Sage.

Pullen, L., Tuck, I., \& Wallace, D.C. (1999). Research priorities in mental health nursing. Issues in M ental $\mathbf{H}$ ealth $\mathbf{N}$ ursing, 20(3), 217-227.

Roberts, B.L. (1999). Activities of daily living: Factors related to independence. In A.S. H inshaw, S.L. Feetham, \& J.L.F. Shaver (Eds.) $H$ andbook of clinical nursing research (563-574). Thousand $O$ aks, CA : Sage.

Sedlak, C., Ross, D., Arslanian, C., \& Taggart, H. (1998). Orthopaedic nursing research priorities: $\mathrm{A}$ replication and extension. Orthopaedic N ursing, 17(2), 51-58.

Shaver, J.L.F. (1999). M anaging sleep and waking behaviors and the symptom of fatigue. In A.S. H inshaw, S.L. Feetham, \& J.L.F. Shaver (Eds.), $\mathrm{H}$ andbook of clinical nursing research (435-447). Thousand $O$ aks, CA: Sage.

Sigmon, H .D., G rady, P.A., \& A mende, L.M . (1997). The N ational Institute of $\mathbf{N}$ ursing R esearch explores opportunities in genetics research. $\mathbf{N}$ ursing O utlook, 45(5), 215-219.

Smith, B., \& M acVicar, M . (1999). M anagement of mobility and altered physical activity. In A.S. H inshaw, S.L. Feetham, \& J.L.F. Shaver (Eds.), $\mathrm{H}$ andbook of clinical nursing research (363-673). Thousand $O \mathrm{aks}, \mathrm{CA}$ : Sage.

Stetler, C.B., \& DiM aggio, G. (1991). Research utilization among clinical nurse specialists. Clinical N urse Specialist, 5(3), 151-155.

Stetz, K.M ., H aberman, M .R., H olcombe, J., \& Jones, L.S. (1995). 1994 O ncology N ursing Society research priorities survey. $\mathbf{O}$ ncology $\mathbf{N}$ ursing Forum, 22(5), 785-789.

Tilden, V.P. (1999). Ethics perspectives on end-of-life care. N ursing 0 utlook, 47(4), 162-167.

Tripp-R eimer, T. (1999). Cultural interventions for ethnic groups of color. In A.S. H inshaw, S.L. Feetham, \& J.L.F. Shaver (Eds.), $\mathbf{H}$ andbook of clinical nursing research (107-120). Thousand O aks, CA: Sage.

Weinert, C., \& Burman, M.E. (1999). The sampler quilt: A metaphor of rural communities. In A.S. H inshaw, S.L. Feetham, \& J.L.F. Shaver (Eds.), $\mathrm{H}$ andbook of clinical nursing research (75-83). Thousand $O$ aks, CA: Sage.

Woods, N .F. (1999). Women's health. In A.S. H inshaw, S.L. Feetham, \& J.L.F. Shaver (Eds.), $\mathbf{H}$ andbook of clinical nursing research (457-458) Thousand O aks, CA: Sage.

Woods, N.F., M itchell, E.S., \& Taylor, D. (1999). From menarche to menopause: Contributions from nursing research and recommendations for practice. In A.S. Hinshaw, S.L. Feetham, \& J.L.F. Shaver (Eds.), $\mathrm{H}$ andbook of clinical nursing research (485-502). Thousand $O \mathrm{aks}, \mathrm{CA}$ : Sage. 